\title{
Assessment of the Attitude of Community Pharmacists and Pharmacy Technicians towards Diarrhea: A Simulated Patient Study in Turkey
}

\author{
Mesut Sancar*, Elif Tezcan, Betul Okuyan and Fikret Vehbi Izzettin \\ Clinical Pharmacy Department, Faculty of Pharmacy, Marmara University, Istanbul, Turkey
}

*For correspondence: Email: sancarmesut@yahoo.com; Tel: + 902163464060

Received: 24 July 2014

Revised accepted: 19 June 2015

\begin{abstract}
Purpose: To evaluate community pharmacists' and pharmacy technicians' counselling practices regarding diarrhea in Istanbul-Turkey using a simulated patient study.

Methods: This study was conducted in a total of one hundred community pharmacies located in two different districts of Istanbul, Turkey. Diarrhea cases involving patients of different age groups were designed and assigned to simulated patients who visited the pharmacies. After leaving a neighbourhood pharmacy, the simulated patients answered a list of questions about the content of the consultation services offered by the pharmacist or the pharmacy technician, including whether or not demographic and medication history was taken, if pharmacological and non-pharmacological recommendations were made, and if any patient education was offered. The duration of the counselling services, the total number of questions asked by the community pharmacists and pharmacy technicians, and the cost of the suggested medications were also evaluated.

Results: The number of pharmacists and pharmacy technicians who counselled simulated patients was 40 and 60, respectively. Pharmacists and pharmacy technicians made little enquiry about the demographics and medical history of the patients. The most common medications recommended by pharmacists and pharmacy technicians were probiotics, either alone or in combination with other medications. Pharmacists took more responsibility for simulated patients than pharmacy technicians did $(p<0.05)$. Pharmacists offered more recommendations to simulated patients when compared with pharmacy technicians (90 vs. $68.3 \%, p<0.05$ ).

Conclusion: In view of their consultant role regarding patient medication, the attitude of pharmacists and pharmacy technicians towards minor illnesses such as diarrhea needs improvement through professional education programs.
\end{abstract}

Keywords: Pharmacist, Pharmacy technician, Counselling practice, Simulated patient

Tropical Journal of Pharmaceutical Research is indexed by Science Citation Index (SciSearch), Scopus, International Pharmaceutical Abstract, Chemical Abstracts, Embase, Index Copernicus, EBSCO, African Index Medicus, JournalSeek, Journal Citation Reports/Science Edition, Directory of Open Access Journals (DOAJ), African Journal Online, Bioline International, Open-J-Gate and Pharmacy Abstracts

\section{INTRODUCTION}

A community pharmacy is one of the health care centres where patients seek self-care solutions based on scientific research for their problems. In order to provide pharmaceutical care in situations involving prescription and non-prescription medications that meets the established standards of their profession, pharmacists must obtain sufficient information regarding patients' demographic data, medical history, and current complaints by asking the patient key questions [1]. Pharmacy technicians are the main auxiliary staff in community pharmacies in Turkey who can dispense and offer counsel about both prescription and non-prescription drugs [2]. 
Many patients visiting community pharmacies ask for advice, including recommendations of medications for treating minor as well as acute illnesses such as diarrhea, constipation, fever, pain or dermatologic problems [3]. A simulated patient method is commonly used for the evaluation of pharmaceutical services in community pharmacies [4-7]. The reason for choosing a simulated patient method in this study is to acquire feedback in a safe and effective way that can be drawn on to improve the continuing professional development of pharmacists. Also, the simulated patient method captures the actual behaviour of pharmacists and pharmacy technicians, which can be compared with selfreported descriptions of pharmaceutical services [8].

The aim of this study was to examine community pharmacists' and pharmacy technicians' attitudes towards diarrhea cases using a simulated patient method.

\section{EXPERIMENTAL}

This study was conducted in a total of one hundred community pharmacies located in two different districts of Istanbul during October and November 2011. One half of the total number of pharmacies $(n=50)$ were located in an urban region, while the other half $(n=50)$ were in a rural region of Istanbul. These community pharmacies were determined by using the randomization method.

The study complied with the Declaration of Helsinki (9) and was approved by the local ethics committee at the Institute of Health Sciences, Marmara University. The required permission for this study was also obtained from the Istanbul Chamber of Pharmacists. Community pharmacists and pharmacy technicians in the districts were informed of the simulated patient study by the Istanbul Chamber of Pharmacists, although they were not made aware of some details such as the exact testing period and subject of this study. The community pharmacists and pharmacy technicians who did not give their consent were excluded from the study; none of the community pharmacies, however, refused to give their consent. Simulated patients were used to evaluate community pharmacists' and pharmacy technicians' approaches to diarrhea cases.

Two different scenarios were designed according to previous stimulated studies [10-12]. In the first scenario, there was a 7-month old baby who had experienced diarrhea for $24 \mathrm{~h}$ (without any unusual smell or blood, and with normal colour). The baby's mother had stopped breast-feeding because of the diarrhea. In the second scenario, a 24-year-old woman complained of diarrhea that had lasted for $24 \mathrm{~h}$ (without any unusual smell or blood, and with normal colour). In both cases the frequency of faecal discharge was two-fold when compared with the patient's normal pattern. Patients experienced mild vomiting; none of them presented fever or any sign of dehydration.

Both simulated patients had no medication history and had never previously taken any medication for diarrhea. In the first scenario, the simulated patient who entered the community pharmacy was the mother of the sick baby, while in the second it was the husband of the sick woman. Simulated patients entered the community pharmacy and stated that his or her family member was experiencing diarrhea. More information was given by simulated patients upon the request of the pharmacists and pharmacy technicians. All simulated patients were informed about diarrhea and trained for their task by clinical pharmacists.

Additionally, in cases where community pharmacists and pharmacy technicians directly referred simulated patients to physicians during the pharmacy visit, the simulated patients would declare that they had already made an appointment with physician for the next day and just wanted to receive information and advice about what to do in the meantime. No products were to be purchased from the pharmacy, and if pharmacists or pharmacy technicians suggested purchasing anything, the simulated patients would respond that these products were already available in their home.

Simulated patients (in the first scenario was the mother of the sick baby and in the second scenario was the husband of the sick woman) filled out a standardized data collection list after they exited each community pharmacy. The interactions between simulated patients with pharmacy workers were not recorded due to ethical concerns. Simulated patients determined if they were talking with a pharmacist or a pharmacy technician by checking the photos of the pharmacists found on the pharmacy wall, which pharmacies in Turkey are obliged to provide.

\section{Statistical analysis}

The cost of medications was calculated based on the products' price in Turkish Lira $(1 \mathrm{TL}=0,56$ USD at November 2011) listed by Turkish Ministry of Health as at the date the present 
study was conducted. Continuous variables were expressed as mean $\pm S D$ and categorical variables were reported as number (frequency). Chi-Square Test or Fisher's Exact Test were performed on categorical variables. Results were assumed to be significant when the $p<0.05$ threshold was reached by all statistical analyses. SPSS 11.0 Package was used for statistical analysis.

\section{RESULTS}

The number of pharmacists and pharmacy technicians who counselled simulated patients was 40 and 60, respectively. Pharmacists gave more recommendations to simulated patients when compared with pharmacy technicians (90 vs. $68.3 \%, p<0.05)$. Eighty-six percent of them spent less than 3 min on the consultation and only $14 \%$ of them provided consultations lasting between 3 and $6 \mathrm{~min}$. Pharmacists spent a statistically significantly higher amount of time consulting simulated patients than pharmacy technicians $(p<0.01$, Table 1$)$.

Table 1: Time spent with simulated patients during the consultation service

\begin{tabular}{lll}
\hline $\begin{array}{l}\text { Duration of } \\
\text { consultation }\end{array}$ & $\begin{array}{l}\text { Pharmacist/ } \\
\text { pharmacy } \\
\text { technician }(\mathbf{N})\end{array}$ & $\begin{array}{l}\mathbf{1}^{\text {st }} \\
\text { scenario/2 } \\
\text { scenario }\end{array}$ \\
\hline$<3$ min & $29 / 57^{*}$ & $41 / 45$ \\
$3-6$ min & $11 / 3^{*}$ & $9 / 5$ \\
\hline
\end{tabular}

* Statistically significant difference between the groups $(p<0.01)$

The mean of the total number of questions asked by pharmacists was statistically higher when compared with that of pharmacy technicians (2.42 $\pm 0.34,1.49 \pm 0.17$; respectively, $p<0.05)$. Also, the mean of the total number of questions asked during the first scenario was statistically higher when compared with the mean of the total number of questions asked during the second scenario (2.52 \pm 0.22 and $1.18 \pm 0.24$, respectively; $p<0.001)$. The distribution of the total number of questions asked by pharmacists or pharmacy technicians is presented in Table 2.

It was found that the pharmacists and pharmacy technicians inquired about the age of the patient at a significantly higher rate in the first scenario than in the second scenario (94\% vs. $52 \%$; $p<$ $0.001)$. There was no significant difference between pharmacists and pharmacy technicians questions relating to the age of the patient (80\% vs. $68.3 \% ; p>0.05)$. On the other hand, it was determined that the pharmacists and pharmacy technicians asked less questions concerning the characteristics of the patient's diarrhea. Interestingly, neither pharmacists nor pharmacy technicians typically asked about the medication history of the patients. However, the pharmacists showed statistically significantly higher interest in the symptoms of the patients, the general appearance of patients' diarrhea and the presence of a fever in simulated patients when compared with pharmacy technicians (27.5 vs. $1.7 \%, 20$ vs. $5 \%$ and 10 vs. $0 \%$, respectively; $p$ $<0.05)$. The results are shown in Table 3.

Table 2: Distribution of the total number of question asked by pharmacists or pharmacy technicians

\begin{tabular}{lcc}
\hline $\begin{array}{l}\text { Total number } \\
\text { of questions } \\
\text { asked }\end{array}$ & $\begin{array}{c}\text { Number of } \\
\text { pharmacists/p } \\
\text { harmacy } \\
\text { technicians (N) }\end{array}$ & $\begin{array}{c}\mathbf{1}^{\text {st }} \text { scenario/2 } \\
\text { scenario }\end{array}$ \\
\hline 0 & $7 / 17$ & $3 / 21$ \\
1 & $11 / 17$ & $11 / 17$ \\
2 & $5 / 11$ & $12 / 4$ \\
3 & $7 / 12$ & $15 / 4$ \\
4 & $3 / 2$ & $3 / 2$ \\
5 & $3 / 1$ & $3 / 1$ \\
6 & $2 / 0$ & $2 / 0$ \\
7 & $1 / 0$ & $1 / 0$ \\
9 & $1 / 0$ & $0 / 1$ \\
\hline
\end{tabular}

Out of the 35 pharmacists and pharmacy technicians, $51 \%$ of them referred the simulated patient directly to a physician, and $49 \%$ of them counselled the patient to see a physician after 2 days of self-monitoring. The baby simulated patient case was significantly more often referred to physicians when compared with the adult simulated patient case (52 \% vs. $18 \%, p<0.01$ ).

In addition, there was a statistically significant difference between the rate at which pharmacists and pharmacy technicians informed the simulated patients about the benefits of and how to monitor the recommended medication $(27.5 \%$ vs. $1.7 \%, p<0.01)$. Although none of them discussed the continuation of breast-feeding the baby in the first scenario, four pharmacists or pharmacy technicians did offer recommendations about baby feeding.

Only two pharmacists asked questions about the dehydration symptoms and informed the simulated patients to keep close watch on any weight changes. Although $41 \%$ of them gave advice regarding nutrition, none of them discussed the importance of hygiene with the simulated patients. The baby simulated patient case elicited significantly more instruction about nutrition by pharmacists and pharmacy technicians when compared with the adult 
Table 3: Questions asked and information provided by pharmacists/pharmacy technicians

\begin{tabular}{|c|c|c|}
\hline Variable & $\begin{array}{l}\text { Number of } \\
\text { pharmacist/pharmacy } \\
\text { technicians }(\mathrm{N})\end{array}$ & $\begin{array}{l}1^{\text {st }} \text { scenario/2 } \\
\text { scenario }\end{array}$ \\
\hline Age of patient & $32 / 41^{*}$ & $47 / 26^{* *}$ \\
\hline Symptoms of patient & $11 / 1^{* *}$ & $9 / 3$ \\
\hline Duration of patient's diarrhea & $17 / 14$ & $18 / 13$ \\
\hline Presence of blood in patient's stool & $1 / 0$ & $1 / 0$ \\
\hline Frequency of patient's diarrhea & $10 / 7$ & $8 / 9$ \\
\hline General appearance of patient's diarrhea & $8 / 3^{*}$ & $7 / 4$ \\
\hline Presence of vomiting in patient & $4 / 2$ & $5 / 1$ \\
\hline Presence of fever in patient & $4 / 0^{*}$ & $2 / 2$ \\
\hline Medication history of patient & $0 / 0$ & $0 / 0$ \\
\hline Nutrition habits of patient & $3 / 2$ & $3 / 2$ \\
\hline $\begin{array}{l}\text { First scenario: the continuation of breast- } \\
\text { feeding the baby }\end{array}$ & $0 / 0$ & $0 / 0$ \\
\hline $\begin{array}{l}\text { Before coming to the pharmacy, the } \\
\text { treatments tried by patient }\end{array}$ & $0 / 0$ & $0 / 0$ \\
\hline $\begin{array}{l}\text { Physician consultation made before } \\
\text { coming to the pharmacy }\end{array}$ & $1 / 2$ & $2 / 1$ \\
\hline $\begin{array}{l}\text { Whether any medication had been utilized } \\
\text { for diarrhea in the past }\end{array}$ & $0 / 1$ & $1 / 0$ \\
\hline $\begin{array}{l}\text { Physician referral made by pharmacist or } \\
\text { pharmacy technician (Total) }\end{array}$ & $17 / 18$ & $26 / 9^{*}$ \\
\hline $\begin{array}{l}\text { Physician referral made by pharmacist or } \\
\text { pharmacy technicians after } 2 \text { days of } \\
\text { monitoring }\end{array}$ & $10 / 7$ & $9 / 8$ \\
\hline $\begin{array}{l}\text { Immediate referral to a physician by } \\
\text { pharmacist or pharmacy technician }\end{array}$ & $7 / 11$ & $17 / 1$ \\
\hline $\begin{array}{l}\text { Information about the importance of } \\
\text { monitoring the recommended medications }\end{array}$ & $11 / 1^{*}$ & $7 / 5$ \\
\hline Recommendations about baby feeding & $3 / 1$ & $4 / 0$ \\
\hline $\begin{array}{l}\text { Information about the importance of } \\
\text { controlling weight changes }\end{array}$ & $2 / 0$ & $2 / 0$ \\
\hline Questions about dehydration symptoms & $2 / 0$ & $2 / 0$ \\
\hline Nutrition recommendations & $21 / 20$ & $29 / 12^{*}$ \\
\hline Hygiene recommendations & $0 / 0$ & $0 / 0$ \\
\hline
\end{tabular}

simulated patient case (58\% vs. $24 \%, p<0.01$ ). The other consultation services given by pharmacists and pharmacy technicians are presented in Table 3.

The most common medication advocated by pharmacists and pharmacy technicians was probiotics, taken alone or combined with other medications. It was also seen that probiotics were advised more for simulated adult patients rather than simulated child patients (74 vs. $52 \%$, $p<0.05)$. Only $10 \%$ of pharmacy professionals recommended oral rehydration methods to treat acute diarrhea. The mean of the total cost of all recommended medications by pharmacists was not significantly lower when compared with pharmacy technicians' recommendations (7.63 \pm $0.83 \mathrm{TL}, 9.05 \pm 0.70 \mathrm{TL}$; respectively, $p>0.05)$. The medications recommended by pharmacists and pharmacy technicians are presented in Table 4. In addition, there was no significant difference in the mean total cost of recommended medications between the two scenarios (7.59 \pm 0.86 TL for 1st scenario, $9.38 \pm$ $0.63 \mathrm{TL}$ for 2 nd scenario, $p>0.05$ ).

Less than half of pharmacy and pharmacy technicians supplied patient education regarding 
Table 4: Medications recommended by pharmacists/pharmacy technicians

\begin{tabular}{|c|c|c|}
\hline Variable & $\begin{array}{l}\text { Number of } \\
\text { pharmacists/ } \\
\text { pharmacy technicians } \\
\text { (N) }\end{array}$ & $\begin{array}{l}1^{\text {st }} \text { scenario/2 } \\
\text { scenario }\end{array}$ \\
\hline No medication & $3 / 6$ & $8 / 1^{*}$ \\
\hline Commercial oral rehydration methods & $4 / 1$ & $5 / 0^{*}$ \\
\hline Probiotics & $19 / 36$ & $18 / 37^{*}$ \\
\hline Anti-motility & $0 / 1$ & $0 / 1$ \\
\hline Intestinal antiseptic & $8 / 11$ & $8 / 11$ \\
\hline Commercial and handmade oral rehydration products & $2 / 1$ & $3 / 0$ \\
\hline Probiotics + intestinal antiseptic & $3 / 2$ & $5 / 0^{*}$ \\
\hline Probiotics + antibiotics & $1 / 0$ & $1 / 0$ \\
\hline $\begin{array}{l}\text { Commercial and handmade oral rehydration products + } \\
\text { probiotics }\end{array}$ & $0 / 1$ & $1 / 0$ \\
\hline $\begin{array}{l}\text { Commercial and handmade oral rehydration products + } \\
\text { probiotics + intestinal antiseptic }\end{array}$ & $0 / 1$ & $1 / 0$ \\
\hline
\end{tabular}

* Statistically significant difference between groups $(p<0.001)$

Table 5: Number of pharmacists or pharmacy technicians who offered patient education regarding recommended medications

\begin{tabular}{lll}
\hline Variable & $\begin{array}{l}\text { Number of } \\
\text { pharmacist/pharmacy } \\
\text { technicians }(\boldsymbol{n})\end{array}$ & $\begin{array}{l}\mathbf{1}^{\text {st }} \text { scenario/2 } \\
\text { scenario }\end{array}$ \\
\hline Aim of the medications & $13 / 19$ & $\mathbf{3 1 / \mathbf { 1 } ^ { * }}$ \\
How to properly use medications & $20 / 26$ & $\mathbf{3 3 / 1 3 ^ { * }}$ \\
How to store medications & $0 / 1$ & $0 / 1$ \\
The duration of medication utilization & $12 / 13$ & $\mathbf{2 3 / \mathbf { 2 } ^ { * }}$ \\
\hline
\end{tabular}

*There is statistically significant difference between groups in this case $(p<0.001)$

recommended medications that included the aim and proper use of medications. On the other hand, twenty-five pharmacists or pharmacy technicians gave information to simulated patients about the length of medication utilization. There was no significant difference between pharmacists and pharmacy technicians concerning patient education items $(p>0.05)$. The simulated patient in the first scenario was significantly more instructed about the aim, preparation and duration of the medications by pharmacists and pharmacy technicians when compared with the simulated patient in the second scenario $(p<0.001)$. The number of pharmacists or pharmacy technicians who gave patient education regarding recommended medications is shown in Table 5.

\section{DISCUSSION}

It was observed that both pharmacists and pharmacy technicians provided consultation to simulated patients in this study. In accordance with a study conducted in Belgium [11], it was seen that the pharmacists asked few questions before suggesting an appropriate treatment. Similar to other studies [12,13], questions about the medication history of the patient, which can be used to rule out drug-induced diarrhea, were also not asked by either pharmacists or pharmacy technicians in this study.

In a study whose aim was to determine the knowledge and attitude of pharmacy staff towards acute diarrhea in children in Vietnam, it was found that the most common questions asked by pharmacy staff were about demographics and the characteristics of the diarrhea. However, medication history and life style changes that could improve diarrhea symptoms were less frequently asked about [14]. The most common medication that was recommended by pharmacists and pharmacy technicians was probiotics, used as a single agent or combined with other medications. Driesen et al [11] also found that probiotics were the most frequently suggested products for acute diarrhea in an 8-month-old baby. The World Health Organization (WHO) recommends oral rehydration methods for acute diarrhea as a safe and effective treatment choice [15], and a few pharmacists and pharmacy technicians did recommend oral rehydration methods to simulated patients in this study. In contrast, the percentage of pharmacists advising oral rehydration methods in other studies was higher 
than the percentage observed in the present study $[12,16-19]$.

In a recent article, which had the aim of assessing non-prescription medication recommendations of pharmacists with the simulated patient method, it was observed that 8 $\%$ of the participants were advised to try oral rehydration in childhood diarrhea cases [20]. As already suggested in Driesen et al [11], in the present study, concerns related to medication costs would probably be the main reason why probiotics were the most preferred treatment, over oral rehydration products. The percentage of pharmacy workers irrationally dispensing antibiotics for acute diarrhea in another study [12] was higher than what was observed in the present study, as only one pharmacist recommended antibiotic combined with probiotics for the simulated patient.

Some observations can also be made about nonmedical recommendations by pharmacy workers. Although none of them asked questions about the breast-feeding of the baby in the first scenario, four pharmacists and pharmacy technicians did give recommendations about baby feeding. Although less than half of them gave advice regarding nutrition, none of them discussed the importance of hygiene with the simulated patients. These results were similar to those of previous studies [5,11]. In accordance with one previous study [11], only two pharmacists informed simulated patients about dehydration symptoms and the importance of controlling weight changes.

Past studies have suggested that differences between contrasting simulated scenarios might significantly influence the results in many simulated patient studies [21], and our current study was also consistent with this theory. When considering two scenarios involving simulated patients of varying ages, the approaches of pharmacists and pharmacy technicians towards diarrhea cases that related to patient education, physician referrals and nutritional instruction were all significantly different $(p<0.05)$.

\section{CONCLUSION}

Overall, pharmacists and pharmacy technicians provided insufficient counselling to simulated patients with diarrhea. While the most important role of the pharmacists is preventing, determining and solving drug-related problems; none of the pharmacists asked about the simulated patients the medications they had been using that might have induced diarrhea. It is important to improve the knowledge of pharmacists and pharmacy technicians towards these minor illnesses, such as the appropriate time to direct patients to physicians and the appropriate recommendation of over the counter (OTC) medications. The attitudes of pharmacists and pharmacy technicians towards minor illnesses such as diarrhea needs to be improved through welldesigned professional education programs.

\section{Limitations of the study}

The approach of pharmacists and pharmacy technicians towards different patient scenarios by methods that take data changes over time into account was not evaluated. Also, the demographic data of pharmacists and pharmacy technicians could not be collected because of the constraints of the simulated patient method that was selected for the present study. Finally, the sample size of the present study needed to be limited in order to draw general conclusions about the data.

\section{REFERENCES}

1. Chua SS, Ramachandran CD, Paraidathathu TT. Response of community pharmacists to the presentation of back pain: a simulated patient study. Int J Pharm Pract. 2006; 14: 171-178.

2. Apikoglu-Rabus S, Sancar M, Okuyan B, Izzettin FV. Turkish pharmacy technicians' counseling practices and attitudes regarding emergency contraceptive pills. Afr J Pharm Pharmacol. 2011; 5: 60-66.

3. World Health Organization Department of Essential drugs and Other Medicines. (Online). [Accessed 27 Apr 2012]. Available in: http://apps.who.int/medicinedocs/ pdf/whozip32e/whozip32e.pdf.

4. Kippist C, Wong K, Bartlett D, Saini B. How do pharmacists respond to complaints of acute insomnia? A simulated patient study. Int $J$ Clin Pharm. 2011; 33: 237-245.

5. Norris PT. Purchasing restricted medicines in New Zealand pharmacies: results from a "mystery shopper" study. Pharm World Sci. 2002; 24: 149-153.

6. Berger K, Eickhoff C, Schulz M. Counselling quality in community pharmacies: implementation of the pseudo customer methodology in Germany. J Clin Pharm Ther. 2005; 30: 45-57.

7. Toklu HZ, Akici A, Oktay S, Cali S, Sezen SF, KeyerUysal M. The pharmacy practice of community pharmacists in Turkey. Marmara Pharm J. 2010; 14: 53-60.

8. Watson MC, Bond CM, Grimshaw J, Johnston M. Factors predicting the guideline compliant supply (or nonsupply) of non-prescription medicines in the community pharmacy setting. Qual Saf Health Care. 2006; 15: 53-57. 
9. World Medical Association Declaration Of Helsinki, Ethical Principles For Medical Research Involving Human Subjects. [Accessed 15 Jan 2015]. Available in: http://www.wma.net/en/30publications/10policies/ b3/17c.pdf

10. Weiss MC, Booth A, Jones B, Ramjeet S, Wong E. Use of simulated patients to assess the clinical and communication skills of community pharmacists. Pharm World Sci. 2010; 32: 353-361.

11. Driesen A, Vandenplas $Y$. How do pharmacists manage acute diarrhoea in an 8-month-old baby? A simulated client study. Int J Pharm Pract. 2009; 17: 215-220.

12. Saengcharoen $W$, Lerkiatbundit $S$. Practice and attitudes regarding the management of childhood diarrhoea among pharmacies in Thailand. Int J Pharm Pract. 2010; 18: 323-331.

13. Karim R, Ramdahin $P$, Boodoo JR, Kochhar A, Pinto Pereira LM. Community pharmacists' knowledge and dispensing recommendations for treatment of acute diarrhoea in Trinidad, West Indies. Int J Clin Prac.t 2004; 58: 264-267.

14. van Duong $D$, van Le $T$, Binns CW. Diarrhoea management by pharmacy staff in retail pharmacies in Hanoi, Vietnam Int J Clin Pract. 1997; 5: 97-100.

15. World Health Organization (Online). [Accessed 27 Apr 2012] Available in: http://whqlibdoc.who.int/ publications/2005/9241593180.pdf.
16. Goodburn E, Mattosinho S, Mongi P, Waterston $T$. Management of childhood diarrhoea by pharmacists and parents: is Britain lagging behind the Third World? BMJ. 1991; 302: 440-443.

17. Lapeyre-Mestre M, Pin M. Management of acute infantile diarrhoea: a study on community pharmacy counseling in the Midi-Pyrenees region. Arch Pediatr. 2004; 11: 898-902.

18. Aktekin M, Erozgen C, Donmez L. Pharmacy approach to a case of acute diarrhoea with dehydration in Antalya, Turkey. Public Health. 1998; 112: 323-326.

19. Ogbo PU, Aina BA, Aderemi-Williams RI. Management of acute diarrhea in children by community pharmacists in Lagos, Nigeria. Pharm Pract (Granada). 2014; 12: 376.

20. Mesquita $A R$, de Oliveira Sá $D A$, Santos $A P$, de Almeida Neto A, Lyra DP Jr. Assessment of pharmacist's recommendation of non-prescription medicines in Brazil: a simulated patient study. Int J Clin Pharm. 2013; 35: 647-655.

21. Puumalainen II, Peura SH, Kansanaho HM, Benrimoj CSI, Airaksinen MSA. Progress in patient counselling practices in Finnish community pharmacies. Int $\mathrm{J}$ Clin Pharm. 2005; 13: 149-156. 